\title{
12 WEB INFORMATION SYSTEMS MANAGEMENT: PROACTIVE OR REACTIVE EMERGENCE?
}

\author{
Kristin R. Eschenfelder \\ School of Library and Information Studies \\ University of Wisconsin, Madison \\ Madison, Wisconsin 53706 \\ U.S.A.
}

Steve Sawyer

School of Information Sciences and Technology

Pennsylvania State University

State College, Pennsylvania 16803

U.S.A.

\section{INTRODUCTION}

In this paper, we present an analysis of the ongoing maintenance and enhancement of web based information systems (web IS). Our goals are to extend recent theorizing about information systems (IS) maintenance and enhancement, and offer a context-rich theoretical characterization of web IS maintenance and enhancement developed from field data. To achieve these goals, we introduce, describe, and apply recent systems analysis theorizing that examines post implementation maintenance and enhancement activity and blurs the traditional information systems development (ISD) boundaries between systems development and systems maintenance. We then apply the systems development theorizing to four case sites. Our subsequent discussion and analysis allows us to both extend this theorizing based on our field data and present a context-rich theoretical characterization of web IS management.

Recently, several theorists have pointed to the dynamic maintenance needs of some information systems. Orlikowski (2000) refers to these IS as "reconfigurable technology." Truex and Baskerville (1998) and Truex et al. (1999) refer to their development and maintenance as "emergent." These new portrayals of systems maintenance stand in opposition to traditional conceptualizations that present maintenance as involving relatively isolated, and mostly 
apolitical, set activities focused on changing some computing "artifact." The typical depiction of IS maintenance described in texts includes tasks such as correcting faults, improving performance, upgrading software or hardware, updating documentation, and/or adapting the product to a changing environment (Rob and Coronel 2000; Satzinger et al. 2000; Whitten et al. 1994).

We prefer the term "web IS management" to either web IS enhancement or web IS maintenance. This term better reflects the intermingled nature of enhancement, maintenance, and development activity that the new ISD theorizing posits. We use the term "web IS management" in the analysis section of this paper to refer to activities related to the enhancement and maintenance of currently existing web IS. We define web IS as the conglomeration of interlinked, but semi-independent, web sites and applications managed by individuals and groups within an organization and available to outside parties. This definition includes Internet and extranet sites, but excludes intranet sites.

This paper makes an important contribution through its focus on web IS management. The maintenance and enhancement phases of systems development traditionally do not attract much research attention (Bieber et al. 1998; Sommerville 1989; Swanson 1976). Similarly, research on web based information systems (web IS) development has, to date, focused on factors influencing the adoption and implementation of web IS in organizations, not their upkeep (Chatterjee and Sambamurthy, 1997; Damsgaard and Scheepers 2000; Jarvenpaa and Ives 1996; Lamb 1999; Lamb and Davidson 2000; Wong and Romm 1997). Few studies have examined maintenance phase issues for web IS. A brief search of the trade press however, shows that maintenance phase issues for web IS have generated a great deal of attention, suggesting that their management is an increasingly important professional issue (for examples see Brauns 1998; Gibbons 1998 Greenberg 1998; Koch 1997; Miller et al. 1998).

This paper continues in five parts. First, we briefly summarize the ISD theorizing that we draw upon. We then extend this theorizing by presenting two propositions. Second, we briefly describe our study methodology. Third, we present an analysis of the social context of web IS management in order to describe the data that support our propositions. Fourth, we discuss each of our propositions in terms of the work that we drew on from the literature and the data from our study. Fifth, we return to our discussion of the theories that we drew upon and explain how we extend this thinking.

\section{PROPOSITIONS ABOUT SYSTEMS MAINTENANCE AND ENHANCEMENT}

Our focus on web IS management draws on new concepts of information systems development (ISD) (Orlikowski 2000; Truex and Baskerville 1998; 
Truex et al. 1999). Truex et al. conceptualize an "emergent ISD" that is premised on a view of organizations as continually emerging through constant negotiation and consensus building - a "dialectic." Their view suggests that in an environment of continual organizational change, ISD should strive to achieve goals of continuous redevelopment, continual change, dynamic requirements negotiation and incomplete or purposefully ambiguous specifications. Orlikowski also describes certain technologies as "reconfigurable" in that they undergo constant and significant post-implementation change.

Building on these concepts of dynamic ongoing systems management, in this paper we present two propositions. First, we propose distinguishing between proactive and reactive emergence. As presented, emergent principles imply that an organization intentionally cultivate the ISD characteristics of continuous redevelopment, constant change, dynamic requirements negotiation, and incomplete or purposefully ambiguous specifications. These characteristics act as ISD goals and organizations should take steps to modify traditional ISD to obtain these characteristics. We call this "proactive emergent ISD." We propose a second view of emergent ISD: "reactive emergence." Reactive emergence reflects the condition of an organization that does not actively seek emergent ISD. As we describe later in the paper, the data from this study suggest that the maintenance phase in such an organization may have characteristics similar to the proactive emergence ISD goals. The difference lies in the source of the emergent ISD: intentionality vs. circumstance. Proactive emergent ISD goals are deliberate. Reactive emergent characteristics stem from the struggles and negotiations inherent in the socio-technical context of the system within the organization. This is what Truex et al. refer to as the dialectic. It emerges as different individuals and actors react to the web IS in different and possibly conflicting ways that best correspond with their own needs-a mass and uncoordinated set of reactions. Our evidence from a detailed analysis of the social context of web IS management at four case sites highlights the differences between these two ideas. From a proactive perspective, emergent characteristics can be seen as goals. From a reactive perspective, emergent characteristics can be seen as the current expression of the organizational dialectic.

Second, but related to the above, we propose a specific set of reactive emergent characteristics that describe web IS management in the case sites. As described above, reactive emergent characteristics stem from the social context surrounding the system. In our analysis of social context, we use Kling's (Kling et al. 2000, 2001) socio-technical interaction network (STIN) approach. A STIN approach provides a framework for identifying and describing the social context. In doing so, it provides us a means to explain its importance to the ongoing management of the web IS. 


\section{THE RESEARCH APPROACH}

We employed a comparative analysis of web IS management at four large organizations (Yin 1994). We purposefully selected companies that had maintained Internet and/or extranet sites for at least two years in order to guarantee that the web IS in the organizations would be post-implementation systems, and that web IS managers in the companies would be able to discuss problems they had encountered in the management of their web IS. In order to observe the impact of web IS management activity on comparable processes and structures and the impact of these common processes and structures on the web IS management activity, we selected all traditional manufacturing companies as sites.

\subsection{The Research Sites}

Green Co. was a 5,000-employee manufacturer and retailer of agricultural, farming, and gardening products. It traditionally sold the majority of its products through retail stores and sales teams. At the time of the study, Green Co. had at least two on-line catalog sites whose sales had been slowly increasing over time. Green Co.'s use of web IS was led by its corporate IS group. The corporate web IS managers (CWM) provided in-house consulting and project management for most web IS projects. The majority of distributed or business unit web IS managers (DWM) had backgrounds in marketing or communications. Some senior divisional business mangers doubted the value of web IS projects and expressed concern that they would never produce a return on investment.

Blue Co. was a 39,000-employee manufacturer of environmental control equipment, selling and manufacturing on an international basis. Blue Co. primarily sold through distributors, but had recently begun to sell on-line in certain areas and with certain products. Blue Co. also maintained several on-line customer service sites. At the time of the study, participants perceived the senior management of Blue Co. as non-technology savvy and not interested in the web. A highly distributed business, Blue Co.'s divisional IS units enjoyed a great deal of freedom and latitude in their web efforts. Historically, Blue Co.'s DWMs had led the company in the use of web technology.

Grey Co. was a 110,000-employee manufacturer of duplication equipment and computer peripherals. It manufactured and sold on an international basis, both through retailers and sales teams. At the time of initial data collection, the company maintained several on-line customer service sites. By the end of the study period, it had a functional on-line direct sales site. The study period was also a period of transition for the company as it had just migrated all of its 
product data onto one web accessible product database. Participants perceived upper management as uncertain about the role of the web for the company. Similar to Blue Co., Grey Co.'s DWM had also historically enjoyed autonomy and had led the company in use of the web. The CWM in Grey Co., however, had led the product database project and were attempting to exert more influence across the company.

Red Co. was a 160,000-employee manufacturer of distribution systems and transportation equipment in the United States. At the time of data collection, Red Co. maintained several on-line catalog sites for its products. Similar to Blue Co. and Grey Co., Red Co.'s DWM had led the company's use of the web, but Red Co.'s CWM controlled access to all externally accessible web servers within the company and used this access to maintain control over the activities of the DWM.

\subsection{Data Collection and Analysis}

In collecting data, we used the traditional elements of fieldwork: observation, interviews, and archival records. Data used in our analysis include complete transcriptions of each interview, a demographics questionnaire, researcher notes from observations, and background documents drawn from company websites. Data collection began in the spring of 1999 and ended in the summer of 2000. The first author interviewed a total of 18 web IS managers from across the four companies. She interviewed many a number of times.

Initial data analysis employed the analytic induction technique, a cyclical process involving the creation of themes from the data and the subsequent testing of those themes on new data until theoretical saturation is achieved (Glaser and Strauss 1967; Shelley and Silbert 1992). This analysis is more fully detailed in previous work (Eschenfelder 2000; Eschenfelder and Sawyer 2000).

\section{STIN ANALYSIS OF WEB IS MANAGEMENT}

As a framework for our analysis, we use Kling's (Kling et al. 2000, 2001) socio-technical information networks (STIN) to guide our analysis of the reactive emergent characteristics of web IS management. STINs can be defined as "the links and the nature of the social interactions between various participants and technologies...the specific explication of relationships and dynamics of social action" (Kling et al. 2001). Drawing from actor network theory (Latour 1987) and based in the social informatics tradition (Sawyer and Eschenfelder 2001; Kling 2000), a STIN analysis is premised on the belief that 
understanding the use of a technology presupposes understanding of its social context. Accordingly, we believe that understanding web IS management requires understanding the social context in which the management occurs. Further, a STIN analysis conceptualizes social behavior as influencing technical design choices (and vice-versa). Our analysis shows examples of how social behavior influences the choices inherent in web IS management and how the web IS and management practice shape social behavior. Some descriptor elements of a web IS STIN include key actors, organizational and technological history, typical social interactions, and reward structures (Kling et al. 2000, 2001).

In this section, we use these elements to describe the parts of web IS STIN and their influence on web IS management. In describing the web IS STIN, we focus on those elements that illuminate our later discussion of the reactive emergence web IS management characteristics.

\subsection{STIN Element 1: Key Actor Groups}

Table 1 presents the key actor groups in the web IS management STIN and describes their relationship to each other and to the technology. The section continues by describing two important web IS management conflicts that compose part of the web IS management dialectic.

Table 1. STIN Actors

\begin{tabular}{|l|l|}
\hline \multicolumn{1}{|c|}{ ACTOR GROUPS } & \multicolumn{1}{|c|}{ RELATIONSHIP TO WEB IS } \\
\hline $\begin{array}{l}\text { Corporate Web } \\
\text { Managers (CWM) }\end{array}$ & $\begin{array}{l}\text { Work for corporate IS units. Develop corporate rules that govern } \\
\text { total web IS appearance and functioning. Create and maintain main } \\
\text { portal for the company. }\end{array}$ \\
\hline $\begin{array}{l}\text { Distributed Web } \\
\text { Managers (DWM) }\end{array}$ & $\begin{array}{l}\text { Work for distributed business or functional units. Create and } \\
\text { maintain portals for individual divisions or business groups. Create } \\
\text { and maintain individual applications that meet individual business } \\
\text { needs. }\end{array}$ \\
\hline Business Managers & Generate ideas for web IS. \\
\hline External Customers & $\begin{array}{l}\text { Patronize sites. Interact with system to buy products or request } \\
\text { services. Request system enhancements. Expect fast development. }\end{array}$ \\
\hline Internal Customers & Request enhancements to systems. Expect fast development. \\
\hline Corporate Strategists & Set direction for company with regard to Web IS. \\
\hline $\begin{array}{l}\text { Content } \\
\text { Creators/Owners }\end{array}$ & Create, control, and or maintain content for web IS. \\
\hline
\end{tabular}




\subsubsection{Conflict \#1: Who Are The Customers?}

As large and distributed systems, web IS typically have a diverse customer base with diverse information needs and interaction expectations. Part of the dialectic involves deciding which customer set is most important for a given design decision or funding allocation. Recognizing that different divisions or business groups within companies typically serve different sets within this customer base, the different groups concern themselves with the needs of their customer sets more than the needs of other groups' customer sets. They lobby for design decisions that optimize the arrangement of the web IS for their customers set's information needs over the information needs of other customer sets. Part of the web IS dialectic, therefore, involves the negotiation of design or management decisions that will benefit some business groups' customers sets over other business groups' customer sets.

\subsubsection{Conflict \#2: What Governance Structures Work Best?}

Web IS governance structures consist of policies that dictate design and management decisions for the component web sites within a larger web IS. These policies involve a wide array of issues such as degree of coordinated cross information or navigational design, site goals, applications development tools and methodologies, security procedures, content approval processes, etc. As with many types of information systems, one debate surrounding and shaping web IS management is the degree to which centrally controlled governance structures or locally developed governance structures can best promote system success (Brown 1997; Brown and Magill 1998).

In the socio-technical context of web IS management, corporate web IS managers (CWM) see centralized policies as useful tools to encourage uniformity, cross-site sharing, and decrease maintenance costs. Distributed or business unit web IS managers (DWM) see policies as structures that may impede immediate business needs if they restrict decision making options. Therefore, part of the dialectic involves conflicts over which group should have governance and to what degree company policies should shape the component web sites of a web IS and the work of DWM. Another part of the dialectic is the consensus building and negotiation required to create and implement policies.

\subsection{STIN Element 2: Technical Design Choices and Organizational History}

The STIN framework suggests examination of the array of system design choices available to developers and maintainers of information technologies and 
examination of the organizational history in which the information technology exists. This section outlines key features of these elements for organizational web IS.

\subsubsection{Technical Design Choices: Building a Web IS}

Web IS exist in a technical context of architectural choices. Here we describe two technical characteristics of web IS that shape their social context by promoting conflicts, encouraging local control of the web IS and altering power relationships within the organization.

First, it is important to understand that one can maintain web IS on multiple possible platforms and do enhancement work with multiple possible development packages. The platforms and development packages chosen shape the social context surrounding the systems. For example, at many of the case sites, the corporate web management (CWM) group wished to standardize web IS platforms and development packages in order to leverage resources across the company and reduce overall maintenance costs. But distributed web managers (DWM) sometimes made platform and development package choices that did not conform to the corporate standard. These design choice differences often led to political tension between CWM and DWM.

A second important technical characteristic is that developing a web IS is relatively cheap and easy. One can run web IS from a simple server as opposed to a mini computer or mainframe. Further, developing a web IS is comparatively easy. For example, web IS use relatively simple development languages (e.g., JAVA and PERL, compared to $\mathrm{C}++$ ). Also, many of the common applications used today, such as web accessible databases, are available in a template form that does not require years of experience to develop. One web IS manager described the ease of technical site creation:

Lots of people still think the hard point is somehow creating the site...anybody can spin up a web site. You take it out of a box and pull a string out...anybody can take the demo from the vendor and put it out there, change the titles.

Both the relatively cheap costs for web hardware and the relative ease of web development are important for two reasons. First, they encourage the proliferation of web IS within organizations. Further, physical control over a web server and web personnel increases business group commitment to, and control over, web IS applications. Second, business group control over web IS impacts power relationships within companies as both corporate and business units negotiate other aspects of systems design, use, and management. The next section continues by discussing the importance of organizational history. 


\subsubsection{Organizational History: Development and Control}

Organizational history is part of the context surrounding and shaping development and use of the web IS. The organizational history shapes current web IS context through its creation of expectations regarding who would control the web IS within the organization. Three of the four sites included in this study had a history of "grassroots" control of the web IS (Lamb and Davidson 2000). In the three sites, divisions or business units had experimented with the web at very early stages with little or no encouragement or oversight from the corporate IS unit. The last site had no history of grassroots control. Rather, its corporate IS unit had led web development efforts within the organization from the very beginning.

This history of grassroots control created an expectation of future web autonomy in the three organizations. This autonomy-expectation encouraged resistance to corporate efforts to develop greater oversight of web IS management. This resistance manifested itself through disagreement between corporate web managers (CWM) and distributed web managers (DWM) over issues including the appropriateness of content, who should lead web development activities, and who should control access to production servers. In contrast, in the site that had no history of grassroots web development, we observed fewer disagreements between CWM and DWM over control of the web IS.

\subsection{STIN Element 3: Social Interactions}

To further characterize web IS management, the STIN approach suggests looking at two types of dependencies between actor groups: resource dependencies and account taking or referent dependencies. Table 2 outlines major dependencies of both types seen across the four sites.

These dependencies contribute to the ongoing change and conflict in that they shape actors' actions. For instance, a web IS manager who perceives that her job skills need upgrading in relation to her peers (e.g., learning Cold Fusion) might push harder for more technologically sophisticated projects. In another example, the unwillingness of business managers to devote sufficient funds to web content maintenance impedes the ability of web managers to keep content fresh. Finally, the lack of clear corporate goals for the web IS made decision making and resource allocation more difficult. Without knowing overall corporate goals for development of an on-line customer base, business managers had a difficult time deciding how much money to invest in the development of sites promoting on-line business. 
Table 2. Web IS Dependencies

\begin{tabular}{|c|c|c|}
\hline Dependency Type & Actors & Relation to Web IS \\
\hline \multicolumn{3}{|c|}{ RESOURCE DEPENDENCIES } \\
\hline Maintenance funds & $\begin{array}{l}\text { DWM and business } \\
\text { managers }\end{array}$ & $\begin{array}{l}\text { Business managers won't allot } \\
\text { resources to maintain and enhance } \\
\text { current web IS (money, personnel) }\end{array}$ \\
\hline Content & $\begin{array}{l}\text { DWM/CWM and content } \\
\text { contributors }\end{array}$ & $\begin{array}{l}\text { Content contributors won't provide } \\
\text { needed content to DWM/CWM for } \\
\text { web IS. } \\
\text { Content contributors won't maintain } \\
\text { content to standards desired by } \\
\text { DWM/CWM because they lack } \\
\text { interest or they lack time. }\end{array}$ \\
\hline \multicolumn{3}{|c|}{ ACCOUNT TAKING DEPENDENCIES } \\
\hline Being left behind & $\begin{array}{l}\text { DWM/CWM and industry } \\
\text { magazines and peer } \\
\text { organizations }\end{array}$ & $\begin{array}{l}\text { Industry magazines and peer } \\
\text { organizations shape web IS } \\
\text { managers' expectations of what their } \\
\text { web IS should be like and what tasks } \\
\text { they should do in their jobs. }\end{array}$ \\
\hline $\begin{array}{l}\text { Alignment with } \\
\text { organizational goals }\end{array}$ & $\begin{array}{l}\text { Business managers and } \\
\text { corporate policy makers }\end{array}$ & $\begin{array}{l}\text { Business and web IS managers must } \\
\text { match their tactical web IS plans with } \\
\text { overall corporate strategic plans. }\end{array}$ \\
\hline
\end{tabular}

\subsection{STIN Element 4: Reward Structures}

The STIN approach also suggests examination of the incentives and discouragers of web IS management activity. Table 3 lists example incentives and discouragers for both corporate and distributed or business group web managers (CWM and DWM).

In our analysis, we return to these incentives and discouragers in order to explain how they shape the ongoing management of web IS.

\subsection{Summary}

The STIN analysis, through it descriptions of key actors, technical design choices and organizational history, social interactions, and reward structures, provides a representation of the social context encompassing and influencing web IS management. In the remaining two sections, we draw on the STIN analysis to inform our propositions. First, we discuss the distinction between proac- 
Table 3. Incentives and Discouragers

\begin{tabular}{|l|l|}
\hline WEB MANAGEMENT INCENTIVES \\
\hline $\begin{array}{l}\text { Improve the } \\
\text { business }\end{array}$ & $\begin{array}{l}\text { Participants cited the desire to increase their organization's profitability, } \\
\text { market share, and reputation within their market as incentives for main- } \\
\text { taining high quality web IS. }\end{array}$ \\
\hline $\begin{array}{l}\text { Personal } \\
\text { development }\end{array}$ & $\begin{array}{l}\text { Participants had personal incentives for engaging in web IS management } \\
\text { activity including enhancement of skills and good performance } \\
\text { evaluations. }\end{array}$ \\
\hline WEB MANAGEMENT DISCOURAGERS \\
\hline Lack of resources & $\begin{array}{l}\text { Each of the four sites operated within tight fiscal restraints. This } \\
\text { discouraged the investment of resources on web IS management efforts. } \\
\text { It also impeded web managers' ability to ensure the quality of content } \\
\text { created or maintained by others. }\end{array}$ \\
\hline $\begin{array}{l}\text { Top management } \\
\text { disinterest }\end{array}$ & $\begin{array}{l}\text { Within the companies, some of the senior managers did not believe that } \\
\text { the web technology would make a significant contribution to the com- } \\
\text { pany. This belief discouraged investment in web IS enhancements. }\end{array}$ \\
\hline $\begin{array}{l}\text { Management } \\
\text { misunderstanding }\end{array}$ & $\begin{array}{l}\text { Within the companies, some managers did not understand the limitations } \\
\text { and maintenance needs of the web IS. This led them to mis-allocate } \\
\text { funds to inappropriate projects and/or to not allocate sufficient funds for } \\
\text { ongoing management. }\end{array}$ \\
\hline
\end{tabular}

tive and reactive emergence. Then we turn to the observed web IS emergent information system development (ISD) characteristics.

\section{REACTIVE EMERGENCE AND THE SOCIAL CONTEXT OF THE WEB IS}

In this section, we use the STIN analysis outlined above to inform the proposed distinction between proactive and reactive emergence. As we explained in the introduction, an emergent approach asserts that in an environment of purposefully cultivated emergence, ISD should strive to achieve goals of constant change, dynamic requirements negotiation, incomplete or purposefully ambiguous specifications and continuous redevelopment. We also introduced the idea of reactive emergence. It refers to the states of change and conflict seen in organizations that did not actively seek to fulfill emergent ISD goals. We assert that the ISD in these organizations may hold characteristics similar to proactive emergence ISD, but that they differ in terms of their intentionality. In Table 4, we describe the proactive emergent goals in the left 
Table 4. Emergence and Reaction: Web IS Management

\begin{tabular}{|l|l|}
\hline Proactive Emergent Goals & Observed Reactive Emergence Characteristic \\
\hline $\begin{array}{l}\text { Continuous redevelopment/ } \\
\text { always analysis }\end{array}$ & $\begin{array}{l}\text { Observed high levels of maintenance and enhancement } \\
\text { activity. Problems with stale content. Expectations for fast } \\
\text { development. }\end{array}$ \\
\hline $\begin{array}{l}\text { Dynamic requirements } \\
\text { negotiation }\end{array}$ & Disagreement between groups about systems requirements. \\
\hline Unclear specifications & Lack of guidance for goals or purpose of web IS. \\
\hline Flexible, modular architecture & Disagreements about systems architecture. \\
\hline
\end{tabular}

column and the reactive emergent characteristics in the right column. We then continue by discussing how our data led us from the proactive emergence goals to develop the reactive emergence characteristics. In doing so, we explain how our data both supports and extends the theorizing of Truex et al. (1999). Our discussion concludes that the characteristics of web management in the case sites best corresponds with the reactive emergence characteristics. This suggests that it is important to distinguish between proactive emergence and reactive emergence in web IS management.

\subsection{Observed High Levels of Web IS Management Activity}

As suggested by the emergent ISD goals in Table 4, each of the four sites displayed high levels of web IS management activity. In interviews, web IS managers portrayed post implementation web IS management as a period of dynamic, constantly changing systems. For example, each of the case sites had either just undergone, or were currently undergoing, site redesigns. One site had recently moved to a database driven platform, another had redesigned its portal to highlight e-commerce applications, the third and fourth had to redesign under pressure from divisional executives to conform to new corporate guidelines. In interviews, web IS managers spoke of multiple ongoing enhancement projects including the addition of new content, new applications, or redesign of existing content.

According to web IS managers, internal and external customers expected constant system change. This expectation manifested itself in perceived pressure to keep content constantly fresh and changing and pressure to constantly add new features and applications. Further, web managers noted that both internal and external customers expected development and enhancement projects to occur very quickly. As a web IS manager explained: 
The pace of business is really picking up. And so whereas, in our environment, we used to sign up to deliverables in, you know, 12 to 18 months. We'll give you something now, we write contracts where we say, "We'll give you something next week."

Another source of pressure for constant change came from the web managers' social benchmarking with peers. As explained in the STIN analysis, web IS managers feel pressure from the trade press and peers to keep their sites comparable to others' sites. Therefore, external examples of continual change encouraged web mangers to increase the pace of change on their own sites.

In summary, the emergent approach predicts continual analysis and development. Our data supports this view, showing how the pace and breadth of ongoing system management work has increased. Further, drawing on the STIN analysis, it shows how the social context surrounding web IS have contributed to and reinforced this increased level of activity.

\subsection{Disagreements Between Groups about System Requirements}

The emergent ISD goals in Table 4 advocate dynamic requirements negotiation. Data at three of the four case sites support this idea of requirements negotiation. In these sites, disagreements about customer needs among the units managing the components of the web IS made it difficult to establish agreements about overall requirements. For example, at the site with the database driven design, groups hotly debated the ordering and length of fields in the database. At another site, groups debated the appropriateness of certain kinds of site content. In both examples, the final format of data fields, or the inclusion or exclusion of the content, would benefit some units' customer sets over other units' customer sets.

In summary, our data support the contention that systems requirements will be negotiated and changing. As explained by the STIN analysis, the negotiation and change seen at our case sites stemmed from groups trying to maximize design decisions for their particular customers.

\subsection{Lack of Management Guidance}

The emergent ISD goals outlined in Table 4 recommend unclear systems specifications. Data from our case sites concur that specifications for projects 
were typically not well defined. Further, our data show how this lack of definition stemmed from factors described in our STIN analysis.

First, as described earlier, user needs were the subject of debate. Second, at many of the sites, top management had not made clear commitments to, or set explicit goals for, company use of web IS. Thus, few clear high-level corporate goals for web IS management existed. Third, given the newness of the technology, lower level business managers without much technology experience were not always able to describe full specifications for newly requested applications. They might request construction of a site, but not be aware of all the decisions that needed to be made about the aim, content, and ongoing maintenance of the site in order to do so. One web IS manager described his typical interaction with a business manager with regard to the development of a new sub site within the web IS:

We've put up temporary sites with vendors' help in four or five days, brought them back [to business managers] and said, "Is this what you were thinking?" [and they say] "Oh, yeah.....well, how do I get my catalog items? What do I sell? What do I charge?" Those things take months. And that, that's just over and over and over again.

New development, therefore, involved the gradual construction of meaning and shared understanding.

In summary, the emergent perspective advocates unclear specifications for ISD. At the case sites, we observed a lack of guidance from management about the purposes and specifications for the system. This lack of guidance stemmed from disagreements about user needs, lack of top management commitment to, or interest in, the web IS, and from lower level management inexperience with the technology.

\subsection{Disagreements about System Architecture}

The emergent perspective outlined in Table 4 advocates the goal of a flexible, modular architecture for ISD. Our data suggests, however, that establishing the system uniformity requirements required for such an architecture would be difficult. Although corporate web IS managers at each of the sites expressed a great deal of interest in standardizing platforms, software, and development methodologies, most of the case site web IS consisted of a mishmash of home grown solutions. Further, our results suggest that several factors introduced in the STIN analysis will impede standardization of the mishmash. 
First, as described earlier, the relative low cost of hardware, and the relative ease of web development, allowed many groups within the organizations to become involved with web IS development. Second, the varying customer needs and business unit priorities within the organizations contributed to a wide variety of systems needs, some of which required particular platforms or software. Third, the web IS managers' perceived need to move quickly encouraged them to develop and use locally controlled expertise for systems development. This local expertise often did not use the architectures advocated by the CWM. Finally, web manager self-development concerns encouraged them to stay abreast of, incorporate, and master all web IS technology advances. Therefore, attempts to create system wide policies for such things as interface requirements, operating system choices, systems development tool choice, and development methodologies conflicted with many of the key players and incentives described in the STIN analysis.

In summary, the emergent perspective advocates development of a flexible, modular architecture through ISD. At our case sites, the corporate IS group wanted to encourage architectural standardization within their organizations. The data, however, suggest that strong and distinct business unit development needs, the low cost of hardware and relative ease of web development, and personal incentives to learn web development skills discouraged the development and acceptance of architectural standards.

\section{CONCLUSION}

Orlikowski (2000), Truex and Baskerville (1998), and Truex et al. (1999) all suggest that the maintenance phase of IS development is increasingly characterized by high rates of change. Data from our study of web IS support this theorizing. Our data show that web IS maintenance, or what we call web IS management, is highly dynamic. Moreover, our data show how this dynamism stems from the social context of the systems. Our STIN analysis illustrates key portions of the social context including disagreements between groups about systems requirements, reliance on distributed others for content, the lack of top management guidance for goals of the web IS, disagreements about the system architecture, and technology characteristics that create low barriers to entry.

Applying Truex et al.'s emergent ISD goals to web IS management at our four sites, we developed four reactive emergence web IS management characteristics:

(1) A high rate of change and growing dependence on distributed others for content.

(2) Disagreements between groups within the organization about customer needs and expectations, data design, and desired content characteristics. 
(3) A lack of high level goals or guidance for the web IS.

(4) Disagreements between groups within the organization about the systems architecture.

The results from this study further the emergence perspective and lend support to many of the propositions made by Truex et al. and by Orlikowski. For example, the results support their contentions that the maintenance costs of emergent or configurable IS will be, and must remain, high. Each of the four sites were struggling to deploy the necessary resources to support continuous change, enhancement, and redesign of their web IS. The data from this study also support the Truex et al. idea of dynamic requirements negotiation and unclear specifications. Across all sites, our data show that the web IS requirements were always being negotiated and design specifications were constantly unclear.

The results suggest, however, that the case sites did not intentionally set out to achieve all the emergent goals suggested in Table 4. We reframe these goals as characteristics and posit that they stem from the organizational dialectic inherent in the social context of the web IS. This is why we propose a distinction between proactive and reactive emergence. Further, while the current conditions at each of the four sites gave credence to the emergent perspective's goal of a flexible and modular architecture, they also showed how social context factors would impede the achievement of the goal. The corporate management at each case site desired development of such an infrastructure, but the range of socio-technical factors inherent in web IS encouraged the development of unique, home grown systems.

Truex et al. posit that the process of organizational emergence takes the form of a dialectic struggle with constant social negotiation and consensus building. We agree. Our data show that web IS management is a highly sociopolitical activity - a dialectic struggle with constant social negotiation and consensus building (see also Eschenfelder 2001; Eschenfelder and Sawyer 2000). In our phrase "reactive emergence," the reaction refers to the actions of the individual actors within the dialectic as they react to the current situation, to others' actions, and to the inscribed features of the technology. The sum of these reactions creates the conflict that Truex et al. refer to as necessary for emergence.

In summary, web IS systems maintenance is characterized by high rates of change and social conflict. At observed cases, however, change and conflict were not intentional goals. We think they are better described as characteristics of a situation resulting from the socially complex and embedded nature of the technology. 


\section{ACKNOWLEDGMENTS}

This research was made possible by a grant from the Lattanze Center for Executive Education at Loyola College in Maryland. The authors would also like to thank the following people for their helpful comments: Wayne Wiegand, Ethelene Whitmire, and the two anonymous reviewers.

\section{REFERENCES}

Bieber, M., Conger, S., Ives, B., Janko, W., and O'Keefe, B. "What's so Different about the World Wide Web Anyway?" in Proceedings of the Nineteenth Annual International Conference of Information Systems, R. Hirschheim, M. Newman, and J. I. DeGross (eds.), Helsinki, Finland, 1989.

Brauns, M. "Through the Web Wall—and Beyond," CIO, October 1998 (http://www.cio.com/ xnet/oct 98 / braunsnotes.html).

Brown, C. V. "Examining the Emergence of Hybrid IS Governance Solutions: Evidence from a Single Case Site," Information Systems Research (8:1), 19898, pp. 69-94.

Brown, C., and Magill, S. "Reconceptualizing the Context-Design Issue for the Information System Function," Organizational Science (9:2), 1998, pp. 176-194.

Callon, M. and Latour, B. "Unscrewing the Big Leviathan: How Actors Macro-Structure Reality and How Sociologists Help Them to Do So," in Advances in Social Theory and Methodology: Towards an Integration of Micro and Macro-Sociologies, K. D. Knorr-Cetina and A. V. Cicourel (eds.), London: Routledge and Kegan Paul, 1981.

Chatterjee, D., and Sambamurthy, V. "Leveraging the Web Business Potential: The Influence of Organizational and Web Management Characteristics," in Proceedings of the Eighteenth International Conference on Information Systems, K. Kumar and J. I. DeGross (eds.), Atlanta, 1997.

Damsgaard, J., and Scheepers, R. "Managing the Crises in Intranet Implementation: A Stage Model," Information Systems Journal (10), 2000, pp. 131-149.

Eschenfelder, K. R. Comparing the Perceived Problems of Distributed and Centralized World Wide Web System Managers: A Modified Goal Theory Approach, Unpublished Doctoral Dissertation, Syracuse University, 2000.

Eschenfelder, K. R. "Managing Web Information Systems: A Socio-Technical Analysis," in Managing Web Usage in the Workplace: A Social, Ethical and Legal Perspective, M. Anandarajan and C.A. Simmers (eds.), Philadelphia: Idea Group Publishers, 2001.

Eschenfelder, K. R., and Sawyer, S. "Web IS Management Problems: Results From a Post Implementation Field Study," in Proceedings of the Sixth Americas Conference on Information Systems. H. M. Chung (ed.), Long Beach, CA, August 10-13, 2000.

Gibbons, P. L. "Over the Line," CIO, March 1998 (www.cio.com/archive/webbusiness/ 030198_sales_content.html).

Glaser, B., and Strauss, A. The Discovery of Grounded Theory: Strategies for Qualitative Research, Hawthorne, NY: Aldine de Gruyter, 1967.

Greenberg, R. "Intranet Introspective," CIO, August 1998 ( www.cio.com/archive/webbusiness/ 080198_central_content.html).

Jarvenpaa, S., and Ives, B. "Executive Involvement and Participation in the Management of Information Technology," MIS Quarterly, 1991, pp. 205-223.

Kling, R. "Learning About Information Technologies and Social Change: The Contribution of Social Informatics," The Information Society (16:3), 2000, pp. 217-232. 
Kling, R.; McKim, G.; Fortuna, J.; and King, A. "A Bit More to IT: Scientific Communications Forums as Socio-Technical Interaction Networks," manuscript submitted for publication, 2001.

Kling, R., McKim, G., Fortuna, J., and King, A. "Scientific Collaboratories as Socio-Technical Interaction Networks: A Theoretical Approach," in Proceedings of the Sixth Americas Conference on Information Systems, H. Michael Chung (ed.), Long Beach, CA, August 10$13,2000$.

Koch, C. "Authors, Authors Everywhere," CIO, January 1997 (www.cio.com/archive/webbusiness/ 010197 author content.html)

Lamb, R. "Using Intranets: Preliminary Results from a Socio-technical Field Study," in Proceedings of the Thirty-second Hawaii International Conference on Systems Sciences, Los Alamitos, CA: IEEE Computer Society, January 1999.

Lamb, R., and Davidson, E. "The New Computing Archipelago: Intranet Islands of Practice," in Organizational and Social Perspectives on Information Technology, R. Baskerville, J. Stage, and J. I. DeGross (eds.), Boston: Kluwer Academic Publishers, 2000.

Latour, B. Science in Action, Milton Keynes: Open University Press, 1987.

Miller, M., Roehr, A., and Bernard, B. Managing the Corporate Intranet, New York: John Wiley and Sons, 1998.

Orlikowski, W. "Using Technology and Constituting Structures: A Practice Lens for Studying Technology in Organizations," Organization Science (11:4), 2000, pp. 404-428.

Rob, P., and Coronel, C. Database Systems Design, Implementation and Management, Cambridge: Course Technologies, 2000.

Satzinger, J. W. W., Jackson, R., and Burd, S. D. Systems Analysis and Design in a Changing World, Cambridge: Course Technologies, 2000.

Sawyer, S., and Eschenfelder, K. R. "Social Informatics: Perspectives, Examples and Trends," in Annual Review of Information Science (ARIST), B. Cronin and D. Shaw (eds.), 2001.

Shelly, A., and Silbert, E. "Qualitative Analysis: A Cyclical Process Assisted by Computer," in Qualitative Analyse: Computereinstaz inder Socioalforshung, G. Hueber (ed.), Munich: R. Oldenbourg Verlag, 1992, pp. 71-114.

Sommerville, I. Software Engineering, Workingham, England: Addison-Wesley, 1989.

Swanson E. B. "The Dimension of Maintenance," IEEE Society Second International Conference on Software Engineering, Los Alamitos, CA: IEEE Computer Society Press, 1976.

Truex, D., and Baskerville, R. "Deep Structure or Emergence Theory: Contrasting Theoretical Foundations for Information Systems Development," Information Systems Journal (8:3), 1998, pp. 99-118.

Truex, D. P., Baskerville, R., and Klein, H. "Growing Systems in Emergent Organizations," Communications of the ACM (42:8), 1999, pp. 117-123.

Whitten, J., Bentley, L., and Barlow, V. Systems Analysis and Design Methods, Burr Ridge, IL: Irwin, 1994.

Wong, J., and Romm, C. "Establishing Organizational Web Sites: Toward an Integrative Conceptual Framework," Creative Collaboration in Virtual Communities Conference, Wollongong, New South Wales, Australia, 1997.

Yin, R. Case Study Research: Design and Methods, Thousand Oaks, CA: Sage, 1994.

\section{About the Authors}

Kristin R. Eschenfelder is an assistant professor at the University of Wisconsin, Madison's School of Library and Information Studies. Her current research falls in the area of social informatics, and focuses specifically on the 
social nature of large web information systems and how we can improve the human and technical processes required to manage them. Kristin also conducts research in the areas of information policy, looking at how our information and telecommunications laws and regulations shape our configuration and use of information and communications technologies. She can be reached by e-mail at kreschen@slis.wisc.edu.

Steve Sawyer is a founding member of the faculty and an associate professor in the newly formed School of Information Sciences and Technology at the Pennsylvania State University. Steve does social informatics research with a particular focus on studying how people work together and how they use information and communication technologies. Present research programs include investigating how software development can be improved through attending to the social aspects of working together, studying how people adapt to working with large scale information systems implementations (such as enterprise resource packages), and understanding the changes to work and organization due to the increased distribution of computing. Steve can be reached by e-mail at sawyer@ist.psu.edu. 